\title{
Eccentric connectivity index of certain classes of cycloalkenes
}

\begin{abstract}
Let $\mathrm{G}$ be a simple connected molecular graph. The eccentric connectivity index $3(\mathrm{G})$ is defined as $3(\mathrm{G})=X_{\mathrm{V} i} \mathrm{~V}(\mathrm{G}) \operatorname{deg}(\mathrm{v}) \operatorname{ec}(\mathrm{v})$, where $\operatorname{deg}(\mathrm{v})$ denotes the degree of vertex $\mathrm{v}$ and $\mathrm{ec}(\mathrm{v})$ is the largest distance between $v$ and any other vertex $u_{i} G$. In this paper, we establish the general formulas for the eccentric connectivity index of molecular graphs of cycloalkenes.
\end{abstract}

Keyword: Eccentric connectivity index; Molecular graphs; Eccentricity; Cycloalkenes 